\title{
A CONSTRUÇÃO DE UM ESPAÇO DE MOBILIZAÇÃO SOCIAL NA INTERNET E A LUTA PELOS DIREITOS ANIMAIS: UM ESTUDO SOBRE A ANDA
}

\author{
DANDARA FLORES ARANGUIZ \\ Centro Universitário Fransicano \\ Santa Maria, Rio Grande do Sul, Brasil \\ e-mail: dandara.flores@gmail.com
}


A CONSTRUÇÃO DE UM ESPAÇO DE MOBILIZAÇÃO SOCIAL NA INTERNET E A LUTA PELOS DIREITOS ANIMAIS: UM ESTUDO SOBRE A ANDA

Resumo: O presente artigo analisa de que maneira a Internet está sendo utilizada pelos ativistas sociais que lutam pelos direitos animais partindo de um estudo sobre a Agência de Notícias de Direitos Animais, a fim de descobrir quais estratégias comunicativas são empregadas. A partir das análises e observações realizadas, percebe-se que a mídia possui papel fundamental no processo de mobilização social, sustentando o debate, a reflexão, a visibilidade e a organização de ações coletivas.

Palavras chave: Ativismo social na internet; direitos animais; movimentos sociais contemporâneos.

LA CONSTRUCCIÓN DE UN ESPACIO DE LA MOVILIZACIÓN SOCIAL EN INTERNET Y LA LUCHA POR LOS DERECHOS ANIMALES: UN ESTUDIO A CERCA DE ANDA

Resumen: Este artículo examina cómo el Internet está siendo utilizado por los activistas sociales que luchan por los derechos de los animales a partir de un estudio de la Agência de Notícias de Direitos Animais con el objetivo de descubrir que estrategias comunicativas de uso de Internet se emplean. De nuestro análisis y observaciones, se advierte que los medios tienen un papel fundamental en el proceso de movilización social, sosteniendo el debate, la reflexión, la visibilidad y la organización de acciones colectivas.

Palabras clave: Activismo social en la Internet; derechos animales, movimientos sociales contemporáneos.

THE DEVELOPMENT OF AN AREA OF SOCIAL MOBILIZATION AND THE STRUGGLE FOR ANIMALS RIGHT: A STUDY ABOUT ANDA

Abstract: This article examine how the internet is being used by the social activists who fight for animals rights starting with a study of the Agência de Notícias de Direitos Animais in order to find out which communication strategies are used. From our analysis and observations, it is noticed that the media has a key role in the process of social mobilization, sustaining the debate, reflection, visibility and organizing collective actions.

Keywords: Social activism on the internet; animals rights; contemporary social movements. 


\section{CONSIDERAÇÕES INICIAIS}

A proposta de estudo apresentada neste artigo visa elucidar o papel da Internet no processo de conscientização acerca dos direitos animais e analisar como a apropriação das novas tecnologias de informação e comunicação proporciona a formação de novos movimentos sociais e novas formas de ativismo. Para tanto, aborda-se questões sobre o ativismo social na rede e a relação da mídia on-line com as manifestações e movimentos de caráter comunicacional à favor da vida e proteção animal.

Nas últimas décadas, o campo da comunicação passou por diversas mudanças de cunho não só social e cultural como também tecnológico. Muito se tem falado a respeito das transformações ocorridas dentro de nossa sociedade a partir do advento das tecnologias computacionais e dos meios eletrônicos. $O$ surgimento de novas mídias possibilitou a ampliação da circulação de informações. Estas transformações midiáticas, tanto de conteúdo, quanto de suporte, são fruto de uma nova sociedade, na qual, por exemplo, é possível visualizar as novas relações sociais oriundas da contemporaneidade, por meio de mobilizações e reivindicações no ambiente virtual.

Diante da possibilidade de expressão que a Internet concede a vozes, até então, desconhecidas e da viabilidade de argumentação, contestação e discussão de questões de interesse público, esta nova atmosfera tecnológica tem se configurado como uma forma de resistência, que permite aos sujeitos criarem novos tipos de comunicação. A Internet, ao funcionar como um espaço público propício para as discussões de interesse coletivo e de cunho político, social, cultural e ideológico, possibilita a descentralização da informação e do poder dos grandes veículos de comunicação tradicionais. $\mathrm{E}$, sendo assim, ajuda na compensação de informações e na expressão de vozes de minorias, como é o caso dos ativistas pelos direitos animais, que viram na web 2.0 a chance de ampliar o espaço de discussão e diálogo entre os aderentes à causa e atrair novos seguidores.

A Internet vem sendo usada como um canal complementar e, de certo modo, compensatório na divulgação da cobertura de certos acontecimentos ligados à esfera da vida animal. Sites e canais especializados e voltados exclusivamente ao tema em questão, aos poucos fincam suas bases no ciberespaço. Diante deste cenário impactado pelas novas demandas da sociedade, emergem os ativistas em defesa dos direitos animais, que utilizam a web como ex- 
tensão da mobilização off-line, onde a esfera virtual é parte e complemento do real, tornando-se imprescindível à ampliação da visibilidade na luta pelos direitos animais. Frente a estas perspectivas, surge o seguinte questionamento: de que maneira os ativistas sociais utilizam a Internet para ampliar o espaço de discussão acerca do processo de conscientização dos direitos animais?

\section{ATIVISMO SOCIAL E MOVIMENTOS SOCIAIS CONTEMPORÂNEOS}

Agir em coletivo. Essa é uma das premissas do ativismo social. Pensar em ativismo é pensar em formação de grupos, contestação e luta pela transformação de um determinado contexto sociopolítico. Os sujeitos envolvidos no movimento ativista podem agir de forma tática ou estratégica e estão vinculados por uma causa em comum. "A idéia do movimento social seria então, no sentido comum, associada a um conjunto de formas de protesto, e vinculada com um vocabulário de acontecimentos e modos de atuar" (NASI, 2011, p. 30).

Diante de um novo contexto histórico, o da globalização e informatização da sociedade, o ativismo social toma outra forma, com motivações e valores alicerçados na solidariedade e no cooperativismo. As novas formas de organização dos movimentos sociais levam em consideração a incorporação das novas tecnologias da informação e comunicação no planejamento, na articulação e no agir de determinado coletivo social. O ativismo de hoje não se organiza de forma hierarquizada, mas sim heterogênea, na qual a busca de soluções alternativas é motivada pela ação em conjunto, que assume um protagonismo coletivo.

Pode-se dizer que os movimentos sociais nascem em resposta aos contextos histórico-sociais nos quais estão inseridos. São, portanto, os modos como os ativistas sociais se organizam, de maneira coletiva, para expressar suas demandas das mais diversas formas: manifestações, passeatas, marchas, abaixo -assinados, denúncias, atos de desobediência, campanhas, etc.

O novo ativismo contemporâneo recusa as imposições do mercado global, que visa o lucro desenfreado. "O que o movimento antiglobalização está demonstrando, é que as lutas sociais voltaram à cena internacional como fonte de pressão por mudanças que levem às transformações do modelo civilizatório em curso." (GOHN, 2010, p. 47)

Os novos tipos de movimentos sociais combinam as formas já institucionalizadas de interlocução com as novas ferramentas de comunicação. A apropria- 
ção estratégica das tecnologias da informação proporcionou e impulsionou a formação de novos movimentos sociais e novas formas de ativismo. A capacidade de se comunicar ampla e rapidamente permite a troca de experiências entre organizações, associações e movimentos. "Em suma, o novo associativismo é mais propositivo, operativo e menos reivindicativo - produz menos mobilizações ou grandes manifestações, é mais estratégico." (GOHN, 2010, p. 18).

Os recursos tecnológicos têm sido os principais instrumentos utilizados nas ações dos movimentos sociais contemporâneos. São eles que dão uma maior visibilidade e destaque às propostas e manifestações. Esta nova forma de organização, ao pôr em prática seus objetivos e metas, acaba projetando em seus participantes o sentimento de pertença social: os que foram de alguma maneira, excluídos, passam, agora, a sentirem-se pertencentes a algum tipo de ação.

Não há como negar que o cenário atual imprime fortes tendências de transformação na maneira como o novo ativismo social se configura. O que muda e chama a atenção é que os elementos e características já existentes tomaram proporções gigantescas após o uso das novas tecnologias da informação e comunicação por determinados grupos e coletivos. A rede deixou de ser uma estratégia para se tornar uma ferramenta de atuação coletiva na sociedade contemporânea.

Estas transformações, principalmente no uso da informação e comunicação, modificaram as relações de tempo e espaço para os atores sociais envolvidos nos movimentos sociais. A arena de debates passa a ser uma "comunidade virtual transnacional” (SCHERER-WARREN, 1999, p. 71). A informação agora é difundida em tempo real, apropriando-se do novo potencial de interação. Tais características legitimam as mudanças nas formas de atuação e articulação dos movimentos sociais, que têm como matéria-prima, a informação. É possível notar ainda que o compartilhamento desta informação tem sido utilizado como arma pelo ator social, que busca fazer a diferença através dos seus atos. As relações sociais oriundas no cerne dos movimentos sociais contemporâneos se dão de maneira pluralista e ampliam a diversidade cultural ao agregar tipos diferentes de manifestações.

Desta forma, a interlocução entre os novos atores da sociedade civil tende a se articular em rede, de acordo com o novo formato organizacional descentralizado e de poder não-hierarquizado, tornando a Internet principal espaço público de fortalecimento das demandas sociais para ampliar o alcance de suas ações e planejamento de estratégias. 


\section{COMUNICAÇÃO E SOCIEDADE EM REDE}

A partir do que foi mencionado anteriormente, é possível afirmar que a inserção de novas tecnologias no dia-a-dia da sociedade vem transformando cada vez mais as relações sociais. A Internet possibilita uma nova forma de expressão social e a formação de novos grupos. O ciberespaço se apresenta como o lugar onde ocorrem trocas de informações, onde novos tipos de comunicação se estabelecem junto à formação/modificação das relações sociais através das redes digitais interligadas a computadores. Mesmo que ainda existam dúvidas a respeito da obscuridade das relações em rede, é inquestionável a real reconstrução nos padrões de interação social apoiados nos novos recursos tecnológicos, firmando-se o que se pode chamar de sociedade de rede.

Manuel Castells foi quem popularizou o uso do conceito no final da década de 1990 para caracterizar o período histórico em que vivemos, no qual se emerge uma nova estrutura social associada ao surgimento do desenvolvimento do processo de informação.

A era da informação é nossa era. É um período histórico caracterizado por uma revolução tecnológica centrada nas tecnologias digitais de informação e comunicação, concomitante, mas não causadora, com a emergência de uma estrutura social em rede, em todos os âmbitos da atividade humana, e com a interdependência global desta atividade (CASTELLS, 2006, p. 225).

Outros autores, como Pedro Gilberto Gomes, apontam a mudança para um novo ambiente midiático que afeta profundamente a sociedade contemporânea. De acordo com ele, "mais do que uma interação pela técnica, está surgindo um novo modo de ser no mundo, representado pela midiatização da sociedade. A midiatização é a re-configuração de um ambiente comunicacional" (GOMES, 2011, p. 1).Sendo assim, podemos concluir que a sociedade só percebe o que está ao seu redor, seus discursos e os atores sociais envolvidos ao se perceber a partir do fenômeno da mídia. A midiatização de que se fala seria a chave para a compreensão dos fatos e da realidade, e a Internet serve como um contraponto às visões externas construídas pelos meios de comunicação de massa tradicionais. Em plena era da informação, caracterizada pela mudança no modo de se comunicar, impactada pelas apropriações de novas 
tecnologias, a sociabilidade se reconfigura a partir das demandas do indivíduo globalizado. "Nesse contexto [...] manifesta-se uma tendência nas pessoas de se reunirem em grupos sociais visando compartilhar interesses em comum" (CORRÊA, 2004, p.2).

Diante disso, a Internet surge não como uma simples tecnologia, mas sim como o coração de uma nova sociedade, com o rompimento de barreiras sociais, geográficas e espaciais, potencializando e amplificando a capacidade de se comunicar e mobilizar.

\subsection{Usos e estratégias comunicativas dos movimentos sociais na rede}

As relações sociais da sociedade moderna e contemporânea, onde os sujeitos envolvidos na mobilização social buscam transformar certa realidade através das ações e atividades de caráter ativista, exigem novas formas de convocação e mobilização. Estas novas demandas são consequências das transformações sociais e políticas nas quais a sociedade moderna se molda e, além de reconfigurarem o cenário ativista, fazem com que o próprio movimento passe a requerer novas estratégias de interlocução entre atores sociais e sociedade civil.

A comunicação e a informação veiculada pelos movimentos sociais interferem diretamente nas relações sociais. A nova configuração em rede dos projetos mobilizadores já pressupõe "um intenso intercâmbio de informações, que possibilita uma produção contínua e conjunta de conhecimentos acerca da causa a que se referem e a causas correlatas" (HENRIQUES, 2005a, p. 9). Partindo deste ponto de vista, podemos identificar que as lutas sociais adquirem, também, a característica de luta pela visibilidade ao utilizarem ferramentas comunicacionais como estratégias para a legitimação institucional e tornar pública as causas, ações e posicionamento.

Diante dos desafios de mobilização da sociedade em rede, é visível a necessidade de que a comunicação seja tratada de maneira tática e estratégica, com o objetivo maior de que as lutas sociais passem a ter grande abrangência e possam ser melhor compreendidas, sem a mediação dos tradicionais meios de comunicação em massa, além de promover a coletividade da atuação em conjunto e construir, no exercício da função comunicacional, uma identidade do movimento. O papel da comunicação no movimento social é fortalecer o 
vínculo entre os atores envolvidos, possibilitando que os indivíduos passem de beneficiados (receptores de informação) para agentes ativos de mobilização através da participação e colaboração.

A visibilidade passa, assim, a ter papel fundamental na mobilização social para que os movimentos possam ganhar a notoriedade desejada. Rafaela Caetano Pinto (2012) afirma que para que os movimentos sociais atinjam os seus objetivos devem difundir informações com a finalidade de estarem sempre presentes na mídia, considerada instância mediadora da sociedade e do debate público. "Desse modo, eles desenvolvem estratégias que os destaquem na cena midiática para que influenciem a opinião pública e, consequentemente, a agenda política." (PINTO, 2012, p. 49)

Com base na premissa da co-responsabilidade a participação continua sendo o elemento-chave essencial para que a mobilização obtenha bons frutos. Os atuantes deste processo se sentem pertencentes e, desta forma, ajudam a alcançar os objetivos estabelecidos. A rede está a serviço dos movimentos sociais contemporâneos, uma vez que propõe a coletivização da ação, tornando -a mais democrática.

A mídia não só compartilha discursos e informações, como também gera vínculos relacionais entre os cidadãos e a mobilização. Neste sentido, podemos pensar a comunicação como ator social, que faz circular estas informações e atua na interlocução dos sujeitos participantes, aumentando a capacidade mobilizatória. O desafio do uso da comunicação pelos movimentos sociais está no fato de tentar evidenciar, por meio da reflexão sobre as funções e características dos meios e abordagens utilizados, um diferencial, para que o processo de mobilização não finde ali mesmo. "O objetivo é mostrar que a comunicação, planejada a partir de um horizonte ético, passa a ser um dos principais instrumentos para auxiliar o movimento em seu processo de transformação da realidade" (HENRIQUES, 2005b, p. 20).

A comunicação tornou-se imprescindível aos movimentos sociais e passou a ser fator primário na coordenação de ações e de mobilização. O processo comunicativo existente nos movimentos é reflexo das novas demandas da globalização, fomentado pelos usos das novas tecnologias de comunicação e informação e pela intensificação da necessidade de se manter em contato permanente. 


\section{CONSIDERAÇÕES SOBRE O OBJETO DE PESQUISA}

A Agência de Notícias de Direitos Animais - ANDA - difunde na mídia os valores de uma nova cultura, preocupada com a defesa e garantia dos direitos animais. Seu objetivo principal é informar e fazer com que o indivíduo participe de grandes mudanças sociais e políticas. Tem como proposta colocar em pauta assuntos que até então não tiveram espaço na mídia tradicional, sempre com o foco na questão animal. Foi criada em 28 de novembro de 2008, por iniciativa da jornalista Silvana Andrade (que percebeu, na época do surgimento da ANDA, o desinteresse dos jornalistas pela causa ao produzirem matérias que apresentassem um único lado, que não o dos animais) e hoje, é a maior e primeira agência de notícias do mundo dedicada exclusivamente aos assuntos relacionados aos direitos animais.

O grande papel da ANDA é ajudar na disseminação de informações para apresentar ao público o outro lado das notícias, o lado dos animais. Atualmente a comunicação já faz parte do debate sobre a causa animal e, muito disso, deve-se à criação da ANDA, que serviu de canal alternativo, pois os direitos dos animais eram uma questão tratada apenas nas áreas de direito e filosofia.

O portal de notícias possui uma média de 20 mil visitas por dia, com acessos de mais de 80 países por semana (Brasil em primeiro lugar e Portugal em segundo). A agência jornalística conta com uma equipe formada por mais de 45profissionais (jornalistas, filósofos, biólogos, nutricionistas, educadores, advogados, promotores públicos, escritores, publicitários, geógrafos, historiadores, entre outros profissionais), sendo destes, 11 responsáveis pela atualização do site (publicação, edição e revisão). Destaca-se pelo fato de, apesar da atualização contínua, não possuir uma redação fixa, com seu trabalho sendo produzido de maneira remota, com notícias do Brasil e do mundo.

Segundo a presidente-fundadora Silvana Andrade, em entrevista à pesquisadora, o trabalho jornalístico da ANDA é realizado quase que em tempo integral; de segunda a segunda-feira, das $6 \mathrm{~h}$ às $22 \mathrm{~h}$, ininterruptamente. $\mathrm{O}$ fluxo de matéria é sempre contínuo (diminuindo no final de semana) e varia entre 15 e 20 minutos, o que gera cerca de 40 publicações diárias. A ANDA se sustenta com recursos próprios e apoio de alguns colunistas. Pelo fato de ser também uma ONG, aceita doações que colaboram nos projetos sociais e atividades desenvolvidas, como seminários, exposições, debates, shows, promoção de livros e passeios ciclísticos. 

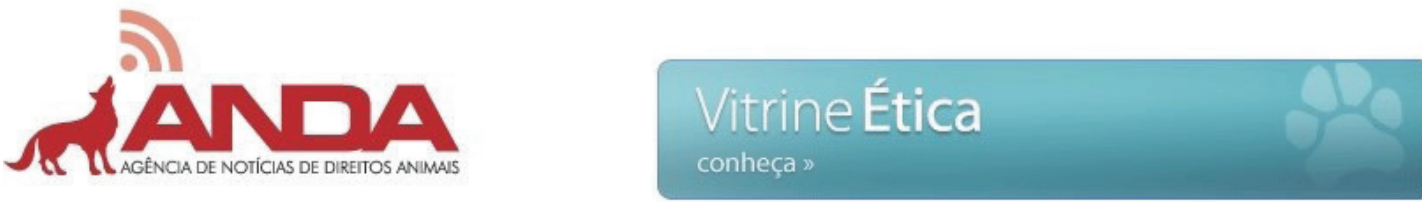

\begin{tabular}{l|l|l|l|l|l|l|l|l|l|l|l} 
Home & Notícias & Artigos & Entrevistas & Blogs e Sites & Sobre a ANDA & Parceiros & Glossário & Depoimentos & Contato & ( ) $f$ [ a \\
\hline
\end{tabular}

Segunda-feira, 8 de outubro de 2012

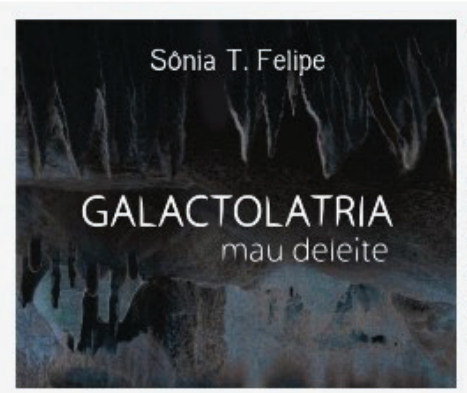

"Galactolatria: mau deleite"

Filósofa Sônia Felipe lança livro que revela os maleficios do leite

Colaboradora da ANDA, Sônia T. Felipe assina a Coluna Questão de ética há quase quatro anos. Seu livro, Galactolatria: mau deleite, é um texto voltado à questão da extraçãao do leite bovino e seus desdobramentos nocivos à vida e ao bem próprio das vacas, à saúde ambiental e humana. Tornar-se vegana, rodeada por onivoros e por comedores ainda afeiçoados à ingestão de alimentos produzidos a partir da secreção da glândula mamária das fêmeas bovinas, é uma decisão que requer alguma determinação da vontade. Para nutrir tal determinação ética, a filósofa Sônia..

Atitude compassiva

Padre adota cães de papeleiro que morreu queimado no RS

Os cães Scooby e Preta conseguiram um novo lar após 15 dias morando na rua. Os animais ficaram abandonados após o tutor deles, o papeleiro Carlos Miguel dos Santos, 45. morrer queimado no barraco $0 .$.

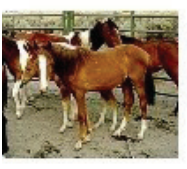

Indústria cruel

Mais cavalos são vendidos para alimentação humana nos EUA

Exploração sem limites Burros explorados carregam roteadores wi-fi para servir parque

\section{em Israel}

A exploração animal não encontra limites para sua criatividade. Em Israel,

burros estão sendo

explorados pela admini.
Cirurgias gratuitas

Programa de

Castração Móvel

criado por vereador de

Sorocaba (SP) já tem

veículo equipado

Criado pela Lei 9.993 , de

autoria do vereador Marinho

Marte (PPS), o Programa de

Castração Móvel da

Prefeitura de Sor.
Vídeo da semana

"Life Defenders": torne-se um

defensor da vida neste game!

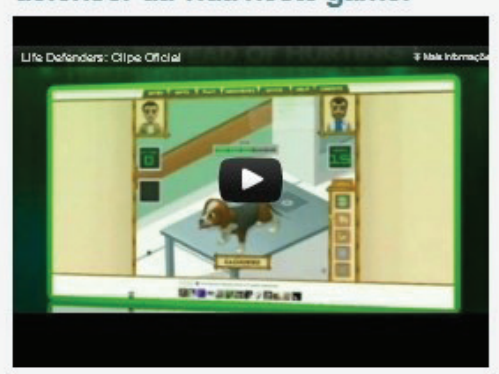

Um grande passo

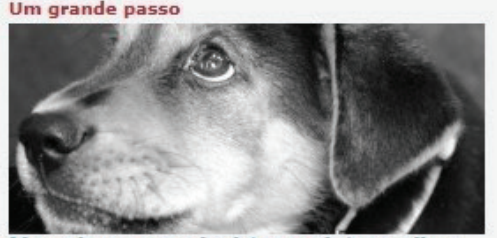

Nova lorque poderá ter registro online de abusadores de animais

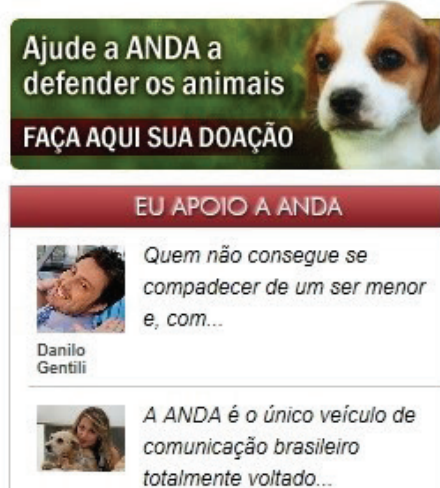

Luisa Mell totalmente voltado.

Ver todos os depoimentos

COLUNAS
Animais e Espiritualidade
A desencarnaçẫo dos irmãos
animais
Grade de programação
Viu um crime? Faça a diferença
e denuncie
Ação Direta
Oanti-especismo mineiro do
Gato Negro
Escrita Libertária
Reiterando a importância e
necessidade do ciberativismo
veg(etari)ano...
Vegano: Desobedecendo
Animais silvestres e animais
domésticos - uma classificação
especista
Direitos dos Grandes
Primatas
NIH engana humanos e
chimpanzés
Vegetariando por ai

Figura 1 - Página inicial da Agência de Notícias de Direitos Animais (ANDA) Fonte: anda.jor.br

\section{PROCEDIMENTOS METODOLÓGICOS}

A construção metodológica nessa pesquisa assume uma abordagem qualitativa; o percurso metodológico utilizado é o estudo de campo, com observações dos sites somadas a entrevistas em profundidade. Para isso, o presente 
trabalho baseia-se em autores que fazem uso de uma aproximação do olhar etnográfico no contexto virtual da Internet. A partir de uma breve observação inicial na Internet percebeu-se o crescimento de portais de movimentos de defesa da causa animal. São sites informativos, guias de combate à exploração animal pelo homem, sites de ONGs envolvidas com a causa, blogs, perfis em redes sociais online e grupos de estudos. Do levantamento obtido, a Agência de Notícias de Direitos Animais (ANDA) foi escolhida para análise neste trabalho. O critério estabelecido foi a caracterização do objeto de pesquisa como um meio de comunicação jornalístico profissional, com uma equipe voltada para a produção de notícias a um público segmentado.

As etapas do procedimento etnográfico da pesquisa foram estabelecidas prevendo entrevista, análise (com base nas observações e descrições do site) e reflexão dos dados coletados. A coleta de dados (observação e análise) se deu durante o mês de setembro. Para dar início ao trabalho de pesquisa, o monitoramento inicial foi feito no período de duas semanas (14 dias consecutivos - de 03 a 17 de setembro), durante quatro (4) horas por dia em horários alternados, a fim de apontar quais os critérios mais focados a partir deste momento. Resolveu-se que durante a observação seriam coletados dados referentes a todo o mês de agosto.

As análises e descrições a seguir foram trabalhadas com base nas observações realizadas durante este período, e na entrevista realizada no dia 28 de setembro de 2012 com a fundadora da Agência de Notícias de Direitos Animais (ANDA) Silvana Andrade. A priori, a entrevista face a face tornou-se opção, para que a principal característica da etnografia não se perdesse - o encontro com o desconhecido e a interação com os atores sociais envolvidos diretamente nas ações. No entanto, a partir de conversas por e-mail e por telefone anteriores à entrevista, percebeu-se que o acompanhamento da rotina produtiva da ANDA não seria possível de se realizar devido à Agência de Notícias não possuir uma redação fixa, com seu trabalho sendo realizado de maneira remota, à distância. Propôs-se, portanto, como alternativa, a mesma abordagem da entrevista presencial só que mediada por um dos meios de comunicação online, o Skype', uma ferramenta de conversação instantânea.

Durante a coleta de dados foi organizada uma tabela (tabela 1) na qual

1 Skype é um software que permite a comunicação pela Internet através de conexões de Voz sobre IP (VoIP). 
cada informação foi distribuída de acordo com sua categoria estabelecida. A observação se fez relevante com a finalidade de tentar entender como se dá a utilização da Internet pelos grupos de proteção animal. As informações coletadas foram sistematizadas de acordo com os seguintes itens: Data (dia do mês analisado); Principais assuntos abordados (síntese dos assuntos mais pertinentes durante o dia); Número de Postagens no dia (quantidade de publicações na categoria Notícias); Títulos das postagens e links (título das publicações e endereço na web); Número de comentários em notícias (quantidade de comentários diretos de internautas por notícia); Número de divulgação em redes sociais (número de pessoas que compartilharam as notícias pelo Twitter, Facebook e Google Plus através da página); Recursos multimídia (utilização de fotos, vídeos, infográficos ou outro tipo de mídia); Assinatura (se a matéria é assinada pela equipe ou se é clipada) e Observações (informações e percepções sobre o conteúdo postado).

\begin{tabular}{|l|c|c|c|c|c|c|c|c|}
\hline Data: & $\begin{array}{c}\text { Principais } \\
\text { assuntos } \\
\text { abordados: }\end{array}$ & $\begin{array}{c}\mathbf{N}^{\circ} \text { de } \\
\text { postagens } \\
\text { no dia: }\end{array}$ & $\begin{array}{c}\text { Títulos } \\
\text { das } \\
\text { postagens } \\
\text { e links: }\end{array}$ & $\begin{array}{c}\mathbf{N}^{\circ} \text { de } \\
\text { comentários } \\
\text { em notícias: }\end{array}$ & $\begin{array}{c}\mathbf{N}^{\circ} \text { de } \\
\text { divulgação } \\
\text { em redes } \\
\text { sociais: }\end{array}$ & $\begin{array}{c}\text { Recursos } \\
\text { multimídia: }\end{array}$ & Assinatura: & Observações: \\
\hline & & & & & & & \\
\hline
\end{tabular}

Tabela 1 - cabeçalho da tabela para coleta de dados

\subsection{Construindo o espaço de mobilização social: análise do corpus}

As análises foram realizadas com base nos eixos sistematizados abaixo, pensados de acordo com as novas demandas, consequência das recentes transformações sociais. A mobilização social sustentada pelas utilizações de ferramentas e estratégias comunicativas permite-nos avaliar, por exemplo, a frequência com que o conteúdo de informações é publicado para manter certa visibilidade; o vínculo estabelecido entre os participantes do movimento e grupos de colaboração; quais os recursos e ferramentas são utilizados para ampliar o canal de disseminação do conhecimento e da causa; a capacidade de mobilização e comunicação ao fazer circular as informações, o tipo de cooperação e colaboração existente que promove a coletivização do movimento contemporâneo. Para isso, as matérias estudadas foram escolhidas de maneira aleatória, conforme se enquadravam nos eixos categorizados.

Para isso, as matérias estudadas foram escolhidas de maneira aleatória, 
conforme se enquadravam nos eixos apontados a seguir:

a) Atualização/instantaneidade - avaliar a periodicidade com que as informações são postadas no site;

b) Interação/repercussão - Como se dá a interconexão entre o público a que o site se refere e os produtores de informação e como repercute (comentários, e-mails, envio de fotos, compartilhamento e divulgação pelas redes sociais);

c) Multimidialidade - analisar quais os recursos multimidiáticos (vídeos, fotos, campanhas publicitárias, podcast, infográficos etc.) são utilizados e de que maneira;

d) Fluxo comunicacional - compreender de que maneira o fluxo de informações é sustentado a fim de manter o diálogo sempre em pauta;

e) Potencial organizacional e de mobilização - observar que tipos de manifestações surgem através das informações divulgadas na ANDA;

f) Participação e empoderamento - analisar as possíveis transformações sociais ocorridas (tipos de ações coletivas) em decorrência do uso da mídia como disseminadora da causa animal.

\subsubsection{Atualização e instantaneidade}

Para a avaliação da periodicidade das informações postadas no site da ANDA foi realizado o monitoramento das publicações. Após a avaliação dos dados coletados finalidade foi feita a contabilização do conteúdo conforme os critérios estabelecidos.

O mês observado (agosto de 2012) teve no total setecentos e quarenta e uma (741) publicações na seção "Notícias" (a contagem ignorou as publicações da seção "Artigos", das colunas e da seção "Vc é o repórter"), contabilizando uma média de 23,9 publicações diárias. Observa-se que a quantidade de notícias publicadas durante a semana é maior do que nos finais de semana. A média de notícias publicadas durante os dias da semana (no período da observação) é de 26,8 publicações diárias; já a média de notícias publicadas nos finais de semana cai para 15,4 publicações diárias. Em decorrência disso, o dia com a quantidade menor de publicações foi um domingo, 5 de agosto, que teve apenas 12 notícias. $O$ dia que obteve mais postagens foi 10 de agosto, sexta-feira, 
com 32 publicações. Apesar do fluxo de publicações diminuir durante os finais de semana, a ANDA consegue manter certa periodicidade das informações publicadas, visto que todo o trabalho é realizado por colaboradores voluntários (jornalistas e correspondentes). As postagens mantêm uma média de intervalo de aproximadamente 20 minutos.

\subsubsection{Interação e repercussão}

Para avaliar de que maneira a interconexão entre o público e os produtores de informação se realiza e como tais informações repercutem no ambiente virtual, foi feita a observação de algumas notícias para apontar suas possibilidades de interação. Um dos recursos encontrados é o compartilhamento e divulgação dos conteúdos através das redes sociais online, como o Facebook, o Twitter, o Orkut e o Google Plus, assim comoo envio de um e-mail com a recomendação da matéria.

Outro aspecto presente e que amplia o diálogo entre os leitores das matérias é a possibilidade de fazer comentários. Uma vez publicado o comentário surge a possibilidade de avaliação da mensagem (se positiva ou negativa), como forma de aprovar ou discordar do que foi escrito, além de poder responder ao comentário.

Podemos perceber que, em conjunto, as ferramentas de comunicação e interação ampliam o canal de conversação entre internautas e produtores de notícias, além de divulgar as informações para outras pessoas (que não precisam necessariamente conhecer o site da ANDA), atuando como um canal de disseminação. Nota-se que, em alguns casos, os usuários conversam entre si por meio dos comentários; às vezes, para concordarem uns com os outros e, outras vezes, para discordarem do que foi dito.

Através dos seus comentários, os leitores deixam as suas impressões sobre o site e sobre a notícia, fazem observações em relação ao ponto de vista dos produtores e editores da ANDA, deixam suas próprias opiniões, acrescentam informações (com o envio de petições, vídeos, links de outras matérias e artigos, etc.), corrigem possíveis erros e criticam certos posicionamentos. A possibilidade de diálogo é importante, na medida em que permite uma verdadeira participação e interação entre emissor e receptor, além de ampliar o espaço de discussão sobre a causa animal. 


\subsubsection{Multimidialidade}

O uso de recursos multimidiáticos pela ANDA costuma facilitar o entendimento das matérias, dando ao internauta a possibilidade de fazer uma leitura mais completa e aprofundada do assunto. Os principais formatos de mídia utilizados nas notícias observadas durante o período de coleta de dados da pesquisa foram vídeos, fotos, hiperlinks e texto. Há, ainda que pequena, a presença de infográficos com a finalidade de explicar o assunto. Percebe-se que a utilização da multimidialidade pela Agência de Notícias se faz presente com a finalidade de ilustrar o conteúdo informacional e também de impactar o público.

Nota-se que o uso de formatos multimidiáticos para apoiar o conteúdo exposto se faz quase sempre necessário, permitindo que a mesma informação possa ser veiculada de diferentes modos, complementando a informação textual. Ao analisar quais recursos multimídia são comumente utilizados pela ANDA, entende-se que tais ferramentas fazem parte do conjunto de estratégias comunicativas que ajudam a difundir e promover informações, colaborando, assim, com o fortalecimento do projeto de mobilização social de luta pelos direitos animais.

Nas situações em que há apenas o texto, a repercussão e interação são baixas, confirmando o importante papel que o conteúdo multimidiático possui na disseminação de informações da ANDA. Nestes casos, o uso de hiperlinks é feito de maneira complementar para a notícia não perder a força.

\subsubsection{Fluxo comunicacional}

Na tentativa de compreender de que maneira o fluxo de informações é sustentado para que o diálogo se mantenha ativo e permanente, foi feita observação amparada no conteúdo veiculado pelo canal midiático. O conteúdo das notícias da ANDA segue a linha de defesa dos direitos animais ao adquirir um posicionamento que busca a transformação social através da difusão de informação, colocando em pauta notícias que habitualmente não possuem espaço na mídia tradicional ou que são abordadas com descaso pela imprensa, de modo geral. É possível perceber tal posicionamento no teor das matérias publicadas, direcionadas à luta pela garantia dos direitos animais e que, por vezes, incentiva atitudes positivas a favor da causa. As notícias de interesse aos 
animais somente são publicadas quando há o aprofundamento do conteúdo abordado no decorrer do texto.

Silvana Andrade afirma, em entrevista à pesquisadora, que a ANDA nunca vai divulgar, por exemplo, uma matéria com o título "Cachorro da raça pitbull ataca e mata criança" sem que haja uma pesquisa e posterior reflexão dos motivos para tal acontecimento, com a perspectiva de mostrar o outro lado do fato; o lado que não aparece na imprensa tradicional.

Além disso, a ANDA faz uso de expressões próprias que caracterizam a mídia alternativa como 'agência de setor' (nas palavras de sua fundadora), com o emprego de palavras como 'assassinados' ao invés de 'mortos','exterminados' no lugar de 'eutanasiados' para relatar crimes ocorridos contra a vida animal; é possível visualizar também a preferência pelo uso das palavras 'prisioneiro' no lugar de 'morador' ou 'atração do Zoológico' e 'prisão' ao invés de 'jaula', para demonstrar as condições em que um chimpanzé se encontra no Zoológico citado em umas das matérias analisadas. $O$ uso destas expressões é feito de forma crítica e intencional, sob o prisma dos direitos animais, a fim de destacar a linha defendida pelo movimento.

Outro aspecto relevante a ser destacado é o tratamento que a ANDA dá às editorias (que na imprensa tradicional são editorias formais). As abordagens das seções já institucionalizadas em outras mídias são, na ANDA, voltadas aos direitos animais. A editoria de Economia, por exemplo, possui informações do tipo: "Crise na Europa agrava abandono de animais" e assim por diante. A sistematização propriamente dita (a listagem das divisões editoriais) não é apresentada no site da ANDA, no entanto, é possível perceber a categorização das editorias no conteúdo informacional das matérias.

Em relação à produção do conteúdo publicado, concluiu-se que, das 741 matérias observadas na amostragem do mês de agosto, 531, cerca de 70\%, foramclipadas, ou seja, não são de autoria da ANDA. Ao todo, foram encontradas 145 fontes de informação distintas referidas. No entanto, nota-se que na maioria das notícias não assinadas, que ou são clipadas ou com informações de outros meios de comunicação, há o acompanhamento de uma Nota da Redação. Ela se faz presente para revelar o posicionamento da ANDA nos fatos ocorridos, para esclarecer informações duvidosas retiradas das fontes citadas ou ainda como complemento ao acontecimento (informações adicionais, notas 
de esclarecimentos das partes envolvidas, sugestões para possíveis soluções, contextualização, etc.). A Nota da Redação exprime a opinião da ANDA através desta manifestação e reconhece que todas as informações ali veiculadas são de sua responsabilidade.

Assim, observa-se que o fluxo comunicacional contínuo de informações é sustentado pelos vínculos interpessoais e coletivos criados a partir do movimento gerado pela multiplicidade de significados e sentimentos envolvidos na defesa da causa animal. As interfaces comunicacionais tornaram-se mais dinâmicas e particularizadas, permitindo, ao mesmo tempo, a coletivização do pensamento (por meio das matérias assinadas e das Notas de Redação, por exemplo) que antes era isolado. Isso tudo acaba gerando confiança aos leitores, ao passo que se sentem mais aproximados e envolvidos com o movimento em questão.

\subsubsection{Potencial organizacional e de mobilização}

Para observar que tipos de manifestações surgem através das informações divulgadas na ANDA buscou-se analisar o poder que as redes de solidariedade criadas no ambiente online exercem na mobilização de pessoas em defesa do movimento. A Internet passou a ter papel central na mobilização social pelo fim da crueldade com os animais ao dar origem a grandes fenômenos de manifestações de cunho reivindicatório e revolucionário. A ANDA defende este ponto de vista abertamente e posiciona-se como um dos representantes (ator social) do grupo social envolvido no debate.

Observa-se que, ao fazer uso das estratégias comunicativas e da própria comunicação de modo geral, a ANDA acaba contribuindo na formação de opiniões, servindo como instrumento de mobilização da sociedade. Um dos recursos mais utilizados para isso é a petição online, que ganhou forças no cenário das tecnologias digitais ao funcionar como instrumento organizacional de participação dos movimentos sociais, em que o cidadão tem a oportunidade de construir ações em prol de determinada causa.

As petições online divulgadas pela Agência de Notícias permitem a rápida adesão dos internautas em torno de projetos em comum, projetando diversas questões ao restante da sociedade. Estes casos de ação coletiva permitem que os próprios leitores postem, por meio da ferramenta de comentário, as petições em forma de revolta ao caso ocorrido, servindo como informação complemen- 
tar à notícia propriamente dita, agindo em volta de um interesse em comum: colaborar para a mudança social através da participação e manifestação do grupo.

Outro exemplo de mobilização que surge através do posicionamento editorial da ANDA são as campanhas que fazem o chamamento online para ações no ambiente offline. Isso mostra o comprometimento dos participantes da causa, que, além de se manifestarem na Internet, também o fazem nas ruas. Outra prática habitual encontrada no período de análise dos dados deste trabalho é o apelo às autoridades, feito através do envio de e-mail, ou contato pelas redes sociais.

A partir dessas reflexões, podemos dizer que há uma reformulação dos indivíduos que se organizam em torno de mobilizações de interesse comum e que são impulsionados, principalmente, pelo agir coletivo possibilitado pelas interfaces tecnológicas. A Internet serve de suporte à diversidade de canais comunicacionais alternativos de reivindicação e manifestação (como a ANDA), caracterizando-se como espaço alternativo e revolucionário ao proporcionar ao indivíduo a experiência de revelar seus sentimentos e ideais para o mundo.

\subsubsection{Participação e empoderamento}

Ao analisar as possíveis transformações sociais ocorridas em decorrência do uso da mídia como disseminadora da causa animal, compreende-se que para uma comunidade ou grupo social ser protagonista do movimento são necessárias práticas que o impulsionem e o promovam. É por meio da participação e empoderamento que a ANDA firma sua capacidade de desenvolvimento e autonomia do movimento ao fazer renascer o espírito de cooperação e compromisso junto às mudanças ocasionadas pela prática do ativismo social na Internet.

Percebe-se que, além de informar sobre os acontecimentos e fatos do mundo animal, a ANDA atua como agente motivador e transformador da sociedade, ao pautar ações sociais de mudança importantes para o movimento de defesa dos direitos animais. A exemplo disto, Silvana Andrade afirma, em entrevista à pesquisadora, que uma das Notas de Redação feitas pela Agência de Notícias já serviu como base de uma sentença num julgamento.

Foi a partir da divulgação deste e mais outros casos de maus-tratos animais que promoveu-se uma comoção coletiva na sociedade, impulsionando 
uma das maiores manifestações nas ruas em prol dos direitos animais no início do ano de 2012. Mais de 170 cidades e capitais brasileiras se mobilizaram num movimento considerado histórico no país, ao pedir o fim da violência aos animais e chamar a atenção de autoridades para que leis fossem alteradas. A convocação foi organizada e planejada na Internet e teve como fator motivador principal as impunidades da justiça para crimes ocorridos contra a vida animal.

O que tudo isso nos revela é a emergência de uma nova sociedade alicerçada na participação de indivíduos e organização de grupos sociais que buscam o processo de mudança e transformação da realidade por meio de ações oriundas, principalmente, das estratégias utilizadas pela comunicação. O processo de empoderamento torna-se elemento fundamental na compreensão dos limites e possibilidades do ativismo social. Tal estrutura nos permite a visualização do engajamento de indivíduos,criando laços de pertencimento e identidade coletiva.

\section{CONSIDERAÇÕES FINAIS}

Um dos principais aspectos observados durante o período de produção deste trabalho foi a capacidade de expressão, do sentimento coletivo caracterizado pelas mobilizações e processos capazes de transformar a sociedade. Vivemos um novo momento na trajetória dos movimentos sociais contemporâneos, onde novas redes de associações ampliam vozes, contribuindo para uma construção social mais democrática. A Internet tornou-se principal palco para ações de participação e empoderamento social, facilitando as ações e atividades dos grupos.

O exercício do poder dos novos movimentos sociais é um conjunto de ações organizadas e estruturadas coletivamente, em função dos objetivos e da representatividade do grupo. A partir das análises e observações realizadas, pode-se concluir que são as estruturas participativas, baseadas num conjunto de estratégias comunicativas, que promovem o reconhecimento do movimento de defesa da causa animal.

A mídia possui papel fundamental no processo de mobilização social atualmente, sustentando o debate, a reflexão, a visibilidade e a organização de ações coletivas. Vê-se surgir novas formas de relacionamentos e novos tipos de vínculos criadores de um canal alternativo de disseminação do conhecimento. Com o desenvolvimento de novas tecnologias de informação e comunicação 
(TICS), grupos de ativistas começaram a se apropriar da Internet e de toda sua potencialidade a fim de dinamizar suas lutas e causas a favor da justiça social.

A construção desta rede maior de ativistas facilitou a intercomunicação entre os indivíduos envolvidos, rompendo barreiras geográficas, sociais e políticas. É preciso, então, reconhecer este novo tipo de ativismo social emergente na esfera pública e civil, que luta pela garantia dos direitos animais. O uso do ciberativismo pelos movimentos sociais contemporâneos tornou-se a principal arma contra a invisibilidade do movimento e a falta de conhecimento técnico específico a respeito, além do descaso com que notícias de crimes contra a vida animal continuam sendo tratadas na mídia tradicional.

\section{REFERÊNCIAS}

CASTELLS, Manuel. Inovação, liberdade e poder na era da informação. In: MORAES, Denis de. (org.) Sociedade Midiatizada. Rio de Janeiro: Maud, 2006. p. 225-231.

CORRÊA, Cynthia Harumy Watanabe. Comunidades virtuais gerando identidades na sociedade em rede.Ciberlegenda. N.13,2004. Disponível em: <http://www.uff.br/ciberlegenda/ojs/ index.php/revista/article/view/226/122>

GOHN, Maria da Glória (org). Movimentos Sociais no Início do Século XXI: antigos e novos atores sociais. 4. ed. Petrópolis, RJ: Vozes, 2010.

GOMES, Pedro Gilberto. Um projeto para o nosso tempo. Instituto HumanitasUnisinos. Março de 2011. Disponível em:

<http://www.ihu.unisinos.br/noticias/41520-um-projeto-para-o-nosso-tempo-artigo-de-pedro-gilberto-gomes>

HENRIQUES, Márcio Simeone. Comunicação, comunidades e os desafios da mobilização social. Anais do XXVIII Congresso Brasileiro de Ciências da Comunicação, Rio de Janeiro - RJ, 2005 a.

MG: Autêntica, 2005b.

(org). Comunicação e Estratégias de Mobilização Social. 2. ed. Belo Horizonte,

NASI, Lara. Usos da Internet na atuação de movimentos sociais em rede: um estudo sobre o Fórum Social Mundial das Migrações. Projeto de Qualificação de Mestrado - Curso de PósGraduação em Ciências da Comunicação. Universidade do Vale do rio dos Sinos, São Leopoldo, 2011.

PINTO, Rafaela Caetano. As estratégias ativistas do Greenpeace para sustentar o debate sobre o meio ambiente na esfera pública. 113f. Dissertação. (Mestrado em Comunicação Midiática) - Programa de Pós-Graduação em Comunicação. Universidade Federal de Santa 
Maria, Santa Maria, 2012. Disponível em:

<http://cascavel.cpd.ufsm.br/tede/tde_busca/arquivo.php?codArquivo=4371>

SCHERER-WARREN, Ilse. Cidadania sem fronteiras: ações coletivas na era da globalização. São Paulo: Hucitec, 1999.

RECEBIDO EM: 30/10/2013

ACEITO PARA PUBLICAÇÃO: 20/11/2013

\section{Dandara Flores Aranguiz}

Jornalista formada pelo Centro Universitário Franciscano de Santa Maria (2012). Integrante do Grupo de Pesquisa Internet, Identidades e Cidadania da Universidade Federal de Santa Maria, sob coordenação da Prof ${ }^{\mathrm{a}}$ Dr $^{\mathrm{a}}$ Liliane Dutra Brignol. 
